\title{
Prevalence of gestational diabetes mellitus: variations related to screening strategy used
}

\author{
José J Jiménez-Moleón, Aurora Bueno-Cavanillas, Juan D Luna-del-Castillo ${ }^{1}$, Miguel García-Martín, \\ Pablo Lardelli-Claret and Ramón Gálvez-Vargas \\ Department of Preventive Medicine and Public Health and ${ }^{1}$ Department of Statistics and Operative Investigation, University of Granada, \\ Avenida de Madrid 11, 18012 Granada, Spain \\ (Correspondence should be addressed to J J Jiménez-Moleón; Email: jjmoleon@goliat.ugr.es)
}

\begin{abstract}
Objective: To determine the prevalence of gestational diabetes mellitus in a large general obstetric population and its variations depending on the presence of risk factors, and to evaluate how the gestational diabetes screening strategies applied might modify the observed prevalence in the population. Design: A retrospective cohort study.

Methods: The study population was a total of 2574 pregnant women. Information about risk factors, screening and diagnosis of gestational diabetes was obtained. Frequency of risk factors under the American College of Obstetrics and Gynecologists (ACOG) and the American Diabetes Association (ADA) criteria, and observed and expected prevalence of gestational diabetes mellitus were calculated and compared for statistical significance.

Results: Age $\geq 30$ years, family history of diabetes, obesity and previous fetal macrosomia were the most frequent risk factors. Under ACOG recommendations, 45\% of our general obstetric population would have been exempt from gestational diabetes mellitus screening, as compared with only $15.5 \%$ under ADA guidelines. Sixty-five patients were diagnosed as having gestational diabetes mellitus, giving an overall prevalence of $2.5 \%$ (confidence interval 2.0-3.2). Among the low-risk women, prevalence values were $0.6 \%$ and $0.5 \%$ respectively under ACOG and ADA criteria, whereas for those presenting one or more risk factors rates were $4 \%$ and $2.9 \%$ respectively.

Conclusions: In our general obstetric population, gestational diabetes mellitus prevalence was found to be approximately six times lower among low-risk gravidae than among the high-risk subjects, suggesting that selective screening might be beneficial. Nevertheless, selective gestational diabetes mellitus screening under ADA criteria seems to entail the same disadvantages as the selective screening strategies without any apparent benefits.
\end{abstract}

European Journal of Endocrinology 146 831-837

\section{Introduction}

Gestational diabetes mellitus (GDM) is defined as a state of carbohydrate intolerance of variable severity and evolution, which develops or is first detected during pregnancy $(1-3)$. Classically, it is associated with an increase in perinatal morbidity and mortality, as well as a greater frequency of long-term complications in the mother and her offspring, consequences that would justify its proper identification and treatment (4-10). Moreover, GDM is the most frequent metabolic problem during gestation: its prevalence is estimated to range between $2 \%$ and $5 \%$ of all pregnancies $(2,3)$ in industrialised countries, although estimations may run anywhere from less than $1 \%$ to over $16 \%$ of all pregnancies (11). The extension and characteristics of
GDM screening and diagnosis $(1-3,12-14)$, and the type of population studied $(15-18)$ are probably the main reasons for this wide variation in prevalence figures. At the same time, methodological deficiencies may lead to biased estimations. According to Hadden (11), 'Most published studies are of an anecdotal type, relating to small groups of patients studied at one maternity hospital, and do not necessarily reflect the true nature of the disorder in that particular country'.

The Sant Vicent Declaration underlines the need to update epidemiological knowledge about diabetes in general, and calls for methodologically rigorous studies able to provide reliable data for comparison (19). With this aim in mind, the present population-based study evaluated: (a) the overall prevalence of GDM in a large (2780) general obstetric population, (b) its 
variations depending on the presence of GDM risk factors and (c) how specific GDM screening strategies may affect figures for observed prevalence.

\section{Subjects and methods}

\section{Design and population}

This was a retrospective cohort study. The eligible population consisted of all the pregnant women giving birth in the San Cecilio University Hospital of Granada (SCUH) between 1 January and 31 December 1995. The SCUH is a tertiary public hospital with 750 beds, operating under the Andalusian Health Service; it is the centre of referral for the southern part of the Province of Granada (Andalusia, Spain), covering a population of approximately 425000 . As a maternity hospital, it covers a population of some 290000 inhabitants. Both family practitioners and obstetricians usually monitor pregnancies on a periodical basis, though high-risk pregnancies are supervised mainly by the obstetrician. Criteria for inclusion in our study were: (a) having regular residence and medical attention within the area of referral of the SCUH, (b) having a singleton pregnancy, (c) making a first visit to the doctor before week 28 of gestation and (d) gestational age at delivery $\geq 28$ weeks. The exclusion criteria were: primary diabetes (type 1 or type 2) or carbohydrate intolerance diagnosed before gestation, a pregnancy not under medical control and pregnancies and deliveries involving a high obstetric risk which, under other circumstances, would not have been attended to in the SCUH. From a total of 2780 deliveries registered in the SCUH in 1995, 2574 $(92.6 \%)$ fulfilled the criteria for inclusion in our study.

\section{Diagnosis of GDM}

Spain's National Health Service has a free prenatal care programme for all pregnant women. The regional Andalusian Public Health Authority (20) recommends that all pregnant women be tested for GDM between weeks 24 and 28 of gestation, with a $50 \mathrm{~g}$ oral glucose challenge test (GCT). Plasma glucose is measured $1 \mathrm{~h}$ after ingestion of the glucose load; a value $\geq 7.8 \mathrm{mmol} / \mathrm{l}$ is considered positive, requiring a standardised $100 \mathrm{~g}$ 3-h oral glucose tolerance test (OGTT) for the confirmatory diagnosis of the disease. In the presence of GDM risk factors, it is recommended that the GCT be moved up to the first medical visit during pregnancy, and if negative then repeated after week 24 of gestation. The $100 \mathrm{~g} \mathrm{3-h}$ OGTT is to be interpreted according to the recommendations put forth by the National Diabetes Data Group (1), with results considered to be indicative of GDM when two or more of the four plasma glucose values are greater than or equal to: $5.8 \mathrm{mmol} / \mathrm{l}$ in a fasting state, $10.6 \mathrm{mmol} / \mathrm{l}$ at $1 \mathrm{~h}, 9.2 \mathrm{mmol} / \mathrm{l}$ at $2 \mathrm{~h}$ and $8.1 \mathrm{mmol} / \mathrm{l}$ at $3 \mathrm{~h}$.

\section{Sources of information and study variables}

The birth register, an official volume kept at all hospitals and filled out as a requirement under Spanish legislation (21), was the primary data source. It contains information about date of delivery, name, age, address, number of the medical record of the parturient, number of previous children and pregnancies, type of pregnancy, antecedents, obstetric formula and information about delivery and the newborn. The maternal health booklet, which contains the data recorded at each monthly checkup during pregnancy (number of visit, week of gestation, maternal weight, blood pressure, general observations, antecedents, results of analytical or ultrasound investigations and specification of any medication or treatment), was also studied for all the gravidae. In cases where some of this information was missing, or the maternal health booklet could not be located, we obtained data through mailings or phone interviews with the mother. Using the above sources of information, the following variables were considered. (a) Outcome variables: performance or not of the GCT and OGTT, week of gestation at testing and results of glucose determinations for both tests. (b) Risk factors: variables considered separately as risk factors for GDM were maternal age ( $\geq 25$ or $\geq 30$ years, according to the criteria of the American Diabetes Association (ADA) (3) or the American College of Obstetrics and Gynecologists (ACOG) (14)), history of diabetes mellitus in a firstdegree relative, chronic hypertension, body mass index $(\mathrm{BMI}) \geq 27 \mathrm{~kg} / \mathrm{m}^{2}$, history of GDM or macrosomia, polyhydramnios, hypertension induced by the pregnancy, suspected large fetus for gestational age, and an obstetric history including two or more miscarriages, perinatal mortality or congenital malformations in previous pregnancies. Furthermore, two new variables were designed: the number of GDM risk factors per woman and classification as either high or low risk for GDM. The high-risk group comprised gravidae with at least one of the aforementioned risk factors and was first defined using ACOG criteria (age cutoff 30 years or older) and then ADA criteria (age cutoff 25 years or over) $(3,14)$.

\section{Analysis of data}

An analysis of losses was carried out first, comparing the women with complete medical and obstetric information with those for whom some relevant information was missing. The Pearson $\mathrm{Chi}^{2}$-test was used to compare proportions, and the Student's t-test and the Mann-Whitney test for the comparison of means.

Two estimations of GDM prevalence were obtained: observed prevalence (number of confirmed cases among the total study population) and expected prevalence. To obtain expected prevalence, we calculated the expected number of GDM cases among those women 
who had not been screened or did not know if they had, and then we added the observed cases plus the expected ones. To estimate the expected number of cases, the observed prevalences for each stratum of women defined by their risk factors were applied. The 95\% confidence interval (CI) for all estimations was calculated by means of the exact method for a binomial. Statistical analyses were performed with SPSS (SPSS Inc., IL, USA) and Epi Info 6.04a (Centers for Disease Control and Prevention, GA, USA) packages.

\section{Results}

While 2574 women fulfilled the inclusion criteria, all relevant clinical and obstetric information was available in 2380 cases $(92.5 \%)$. Screening had been documented in 1962 women $(76.2 \%$ of the study population), was definitely not done in 425 (16.5\%) and was not known in 187 cases (7.3\%). There were no significant differences with regards to the presence or absence of GDM risk factors between this latter group of women and those for whom information about performance and results of GDM screening could be collected (data not shown), except for age: women without data about GDM screening tended to be younger (27.7 versus 28.7 years old; $P<0.05$ ). The GCT gave a positive result in 294 women, 259 of whom $(88 \%)$ also had the OGTT. The confirmatory test was likewise performed for 23 pregnant women who had shown negative in initial screening yet presented some risk factor. Overall, GDM was confirmed in 65 women, meaning an observed prevalence of $3.31 \%(95 \%$ CI 2.57-4.21) among those screened and $2.53 \%(1.95-3.21)$ among the whole cohort.

Table 1 presents the distribution of frequency for each of the GDM risk factors, along with the observed prevalence of GDM for each stratum. Age was clearly the most frequent GDM risk factor for our population. In following ADA criteria, 80.3\% would have required screening merely on the basis of being 25 years or older. This proportion decreased to $41.8 \%$ when the cutoff age of 30 years or over was used (as proposed by the ACOG). Of the remaining GDM risk factors, family history of diabetes (14.8\%), weight over $27 \mathrm{~kg} / \mathrm{m}^{2}(12.3 \%)$ and macrosomial antecedents $(4.9 \%)$ were the most frequent. The greatest observed prevalences of GDM were for the antecedent of GDM itself $(38.1 \%)$, obesity (BMI $\left.\geq 30 \mathrm{~kg} / \mathrm{m}^{2} ; 14.3 \%\right)$ and chronic hypertension (11.5\%).

The distribution of women according to their inclusion in the high- or low-risk group as well as the number of risk factors per woman is given in Table 2 . A total of 1138 women $(44.2 \%)$ did not present any risk factors under ACOG recommendations, compared with only $15.5 \%$ under ADA guidelines. Screening covered $70 \%$ of the women presenting no risk factors. The percentage of coverage increased consistently along with the greater number of risk factors, for both ACOG and ADA criteria $(P<0.001)$.

Table 2 also shows observed and expected GDM prevalences for each group. Based on the distribution of women with regard to risk factors, and in light of the number of cases confirmed among the screened mothers, an additional 13 cases might have been detected in the whole sample (12 if the data-derived ADA criteria is used to compute it): ten among the unscreened subjects and three among the 187 uncertain cases. Thus, if the screening programme had been carried out in $100 \%$ of the population, a maximum of 78 cases of GDM might have been detected, giving an expected prevalence of $3.07 \%$ (CI 2.443.81).

According to ACOG criteria, the observed prevalence was $4.04 \%$ (CI 3.08-5.19) in the high-risk group, as opposed to $0.6 \%$ (CI $0.25-1.26$ ) in the low-risk group. The corresponding expected prevalences, if all the pregnant women had been screened, would be $4.74 \%$ (CI 3.70-5.96) for the high-risk group and $0.88 \%$ (CI $0.42-1.61$ ) for the low-risk group. When groups were defined in accordance with the ADA criteria, the difference between the two estimations decreased: observed prevalences were $2.9 \%$ (CI 2.23$3.69)$ in the high-risk group and $0.5 \%(0.06-1.79)$ in the low-risk group. Regardless of the criteria applied, a marked dose-response relationship was seen between the number of risk factors and GDM prevalence $(P<$ 0.001).

\section{Discussion}

The prevalence of GDM and the distribution of its classical risk factors in general populations of pregnant women are key considerations for determining the optimal GDM screening strategy. There is continued debate between proponents of routine screening for all pregnant women $(1,2)$ and those who propose it strictly for selected populations presenting GDM risk factors (3, 14, 22). Moreover, those who advocate selective screening may not agree on the criteria used to define high-risk women $(3,14)$. The members of the US Preventive Service Task Force state that, to date, no conclusive evidence can be upheld in favour or against routine GDM screening, for which reason its current recommendations are based largely on subjective criteria (22).

The great disparity in the estimations of GDM observed across studies $(11,13,15-17,23-28)$ can further complicate this matter. Previous studies have placed the prevalence of GDM as low as $1 \%$ and as high as $16 \%$. The type of population studied, and the extension and characteristics of GDM screening and diagnosis, may help to explain such differences. Notwithstanding, the degree of selection of the study population is clearly influential, and very selected high-risk 
Table 1 Frequency of GDM risk factors, screening and prevalence of GDM.

\begin{tabular}{|c|c|c|c|c|c|c|c|c|}
\hline \multirow[b]{2}{*}{ Type of risk factor } & \multirow[b]{2}{*}{ No. } & \multirow[b]{2}{*}{$\%$} & \multicolumn{3}{|c|}{ Screen no. $(\%)^{a}$} & \multicolumn{3}{|c|}{ GDM } \\
\hline & & & Yes & No & Unknown & Cases & Prev $^{b}$ & $\mathrm{Cl} 95 \%$ \\
\hline Age $<25$ years & 507 & 19.7 & $351(69.2)$ & 99 (19.5) & $57(11.2)$ & 4 & 0.79 & $0.22-2.01$ \\
\hline$\geq 25-30$ years (ADA criteria) & 991 & 38.5 & $763(77.0)$ & 167 (16.9) & $61(6.2)$ & 21 & 2.12 & $1.32-3.22$ \\
\hline$\geq 30$ years (ACOG criteria) & 1076 & 41.8 & $848(78.8)$ & $159(14.8)$ & $69(6.4)$ & 40 & 3.72 & $2.67-5.03$ \\
\hline $\mathrm{BMI}>27-30 \mathrm{~kg} / \mathrm{m}^{2}$ & 183 & 7.1 & $164(89.6)$ & $17(10.4)$ & $2(1.1)$ & 7 & 3.83 & $1.55-7.72$ \\
\hline$\geq 30 \mathrm{~kg} / \mathrm{m}^{2}$ & 133 & 5.2 & 124 (93.2) & $9(6.8)$ & $0(0.0)$ & 19 & 14.29 & $8.83-21.41$ \\
\hline Family antecedent of diabetes & 380 & 14.8 & $333(87.6)$ & $29(7.6)$ & $18(4.7)$ & 21 & 5.53 & $3.45-8.32$ \\
\hline Antecedent of macrosomia & 127 & 4.9 & $114(89.8)$ & $9(7.1)$ & $4(3.2)$ & 12 & 9.45 & $4.98-15.92$ \\
\hline Antecedent of gestational diabetes & 21 & 0.8 & $21(100.0)$ & $0(0.0)$ & $0(0.0)$ & 8 & 38.10 & $18.11-61.56$ \\
\hline Antecedent of hypertension & 26 & 1.0 & $18(69.2)$ & $7(26.9)$ & $1(3.9)$ & 3 & 11.54 & $2.45-30.15$ \\
\hline Antecedent of fetal death ${ }^{\mathrm{C}}$ & 25 & 1.0 & $23(92.0)$ & $0(0.0)$ & $2(8.0)$ & 0 & - & - \\
\hline Antecedent of congenital malformation & 10 & 0.4 & $9(90.0)$ & $1(10.0)$ & $0(0.0)$ & 0 & - & - \\
\hline Total & 2574 & 100.0 & $1962(76.2)$ & $425(16.5)$ & $187(7.3)$ & 65 & 2.53 & $1.95-3.21$ \\
\hline
\end{tabular}

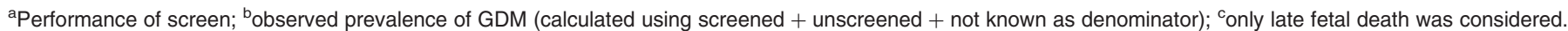

Table 2 Observed and expected GDM prevalence by number of risk factors according to ACOG and ADA criteria.

\begin{tabular}{|c|c|c|c|c|c|c|c|c|c|c|c|}
\hline \multirow[b]{2}{*}{ No. of risk factors per woman } & \multirow[b]{2}{*}{ No. } & \multirow[b]{2}{*}{$\%$} & \multicolumn{3}{|c|}{ Screen no. $(\%)^{\mathrm{a}}$} & \multicolumn{3}{|c|}{ Observed cases of GDM } & \multicolumn{3}{|c|}{ Expected cases of GDM } \\
\hline & & & Yes & No & Unknown & Cases & Prev $^{b}$ & Cl 95\% & Cases & Prev $^{c}$ & $\mathrm{Cl} 95 \%$ \\
\hline \multicolumn{12}{|l|}{ ACOG recommendations } \\
\hline $\begin{array}{l}\text { Low-risk group ( } 0 \text { risk factors) } \\
\text { High-risk group ( } \geq 1 \text { risk factor) }\end{array}$ & 1138 & 44.2 & $800(70.3)$ & $232(20.4)$ & $106(9.3)$ & 7 & 0.62 & $0.25-1.26$ & 10 & 0.88 & $0.42-1.61$ \\
\hline 1 & 997 & 38.7 & $766(76.8)$ & $159(15.9)$ & $72(7.2)$ & 24 & 2.41 & $1.55-3.56$ & 31 & 3.11 & $2.12-4.38$ \\
\hline 2 & 330 & 12.8 & $296(89.4)$ & $27(8.2)$ & $7(2.4)$ & 19 & 3.75 & $2.28-5.80$ & 21 & 6.36 & $3.98-9.56$ \\
\hline 3 & 92 & 3.6 & $83(90.2)$ & $7(7.6)$ & $2(2.2)$ & 11 & 11.96 & $6.12-20.39$ & 12 & 13.04 & $6.93-21.68$ \\
\hline 4 & 17 & 0.7 & $17(100.0)$ & $0(0.0)$ & $0(0.0)$ & 4 & 23.53 & $6.81-49.90$ & 4 & 23.53 & $6.81-49.90$ \\
\hline Total of $1-4$ & 1436 & 55.8 & $1162(80.9)$ & $193(13.4)$ & $81(5.7)$ & 58 & 4.04 & $3.08-5.19$ & 68 & 4.74 & $3.70-5.96$ \\
\hline \multicolumn{12}{|l|}{ ADA recommendations } \\
\hline $\begin{array}{l}\text { Low-risk group ( } 0 \text { risk factors) } \\
\text { High-risk group ( } \geq 1 \text { risk factor) }\end{array}$ & 400 & 15.5 & $259(64.8)$ & $88(22.0)$ & $53(13.3)$ & 2 & 0.50 & $0.06-1.79$ & 3 & 0.75 & $0.15-2.03$ \\
\hline 1 & 1526 & 59.3 & $1129(74.0)$ & $281(18.4)$ & $116(7.6)$ & 20 & 1.31 & $0.80-2.02$ & 27 & 1.77 & $1.17-2.56$ \\
\hline 2 & 506 & 19.7 & 441 (87.2) & $48(9.5)$ & $17(3.4)$ & 23 & 4.55 & $2.90-6.74$ & 26 & 5.14 & $3.38-7.44$ \\
\hline 3 & 115 & 4.5 & 106 (92.2) & $7(6.1)$ & $2(1.7)$ & 14 & 12.17 & $6.82-19.58$ & 15 & 13.04 & $7.49-20.26$ \\
\hline 4 & 27 & 1.0 & $27(100.0)$ & $0(0.0)$ & $0(0.0)$ & 6 & 22.22 & $8.62-42.26$ & 6 & 22.22 & $8.62-42.26$ \\
\hline Total of $1-4$ & 2174 & 84.5 & $1704(78.4)$ & 336 (15.5) & $134(6.2)$ & 63 & 2.90 & $2.23-3.69$ & 74 & 3.40 & $2.68-4.25$ \\
\hline Total of ADA recommendations & 2574 & 100.0 & $1962(76.2)$ & $425(16.5)$ & $187(7.3)$ & 65 & 2.53 & $1.95-3.21$ & 78 & 3.03 & $2.42-3.75$ \\
\hline
\end{tabular}

${ }^{a}$ Performance of screen; ${ }^{b}$ observed prevalence of GDM; ${ }^{c}$ expected prevalence of GDM (if all pregnant women had been screened). 
populations will probably not reflect prevalence trends in the general population. In contrast with many other studies based on small and/or very selected cohorts of gravidae $(11,15,17,24-26,28)$, the main strength of the present population-based study is that the sample size is large enough to yield valid and accurate estimations for GDM prevalence as well as for the frequency of GDM risk factors in a general European obstetric population.

The figures we obtained for observed and expected GDM prevalence, respectively $2.53 \%$ and $3.03 \%$, are consistent with the roughly $2-3 \%$ prevalence expected among white pregnant women from non-selected populations of industrialised countries (2, 3, 11, 27-29), yet lower than rates reported in studies of very selective populations $(11,15,17,24-26,30,31)$. When these figures are broken down into women with/without GDM risk factors, our findings are also consistent with those of other population-based studies (31-33).

Analysis of the risk factors showed the most frequent ones to be older age, family history of diabetes, obesity and macrosomial antecedents. This same order of importance is documented in other studies $(23,30$, $31,34,35)$. Yet it is noteworthy that our survey identified the antecedent of GDM itself in only $0.8 \%$ of the women, a frequency much lower than that reported in other series $(30,35)$. A relatively low parity among our population and the limited frequency of screening and diagnosis of GDM before 1995 in our province may partially explain our low figure for this risk factor. In another Spanish study, Corcoy et al. (24) identified the antecedent of GDM in $1.01 \%$ of the gravidae (24), similar to our results. The fact that there were only three non-white pregnant women in our cohort makes it impossible to analyse race ethnicity as a GDM risk factor.

The variations in GDM prevalence depending on the strata of maternal risk factors observed in our study are largely in agreement with earlier studies $(16,17,24$, $27,28,32,34)$. The greatest prevalence of GDM was for the antecedents of the disease itself in previous pregnancy, obesity and chronic hypertension. The relationship between obesity, hypertension and carbohydrate intolerance is well documented, and continues in pregnancy. Obesity is a noteworthy risk factor for diabetes in general and GDM in particular. The frequency of GDM increases with the BMI of the woman. Given that obesity is a problem more and more frequent in industrialised countries, and is one GDM risk factor that might be reduced, it would seem to be the most appropriate objective for GDM prevention programmes.

Using ACOG criteria, just over half the women of our study (55.8\%) presented one or more of the established risk factors, a proportion within the range reported by other studies using the same age cutoff $(40-60 \%)(23$, $30,34,35)$. Yet when using the ADA criteria (3), $84.5 \%$ presented some risk factor, meaning that only $15.5 \%$ would be in the low-risk group exempt from
GDM screening. In light of this situation, the debate over universal versus selective screening would lose significance under the ADA criteria. In contrast, this debate is highly relevant if we accept the ACOG criteria, according to which approximately $50 \%$ of gravidae would be exempt from selective screening. Moreover, the proportion of cases of GDM that would go undetected under a policy of selective screening would be $10-12 \%$ with ACOG criteria, as opposed to $3-4 \%$ under the ADA recommendations. The importance of underdetecting GDM should be assessed in the context of short- and long-term consequences for the mother and newborn, including the impact of GDM treatment on them. These aspects of the disease still remain unclear $(22,29,36,37)$.

The estimated prevalences we observed in women with no risk factors under the ACOG or ADA guidelines were $0.6 \%$ and $0.5 \%$ respectively. That is, per 1000 gravidae, one case of GDM might go undetected using the ACOG screening criteria compared with ADA criteria. If we bear in mind that 450 women would be exempt from screening under the ACOG recommendations, yet only 150 exempt under the ADA criteria and if, moreover, we consider the cost and complexity of selective screening programmes, the ADA recommendations would not offer any clear advantages over universal screening in a population such as ours.

Regarding the methodology applied in our study, its retrospective character could generate problems related to a selective follow-up bias and/or a classification bias for some of the variables collected. With regard to the former, we acknowledge the loss of those pregnant women who miscarried, though it is unlikely that any potential miscarriages would be associated with GDM. Furthermore, losses of gestating women delivered at a private hospital are very low (approximately 8\% in our area) because of the free and universal coverage of the Spanish Health System. The analysis of losses when medical records were located but some information was missing, on the other hand, suggests a profile for the group of 'missing data' as younger women and with fewer GDM risk factors. This would suggest a lower frequency of GDM as well: expected prevalence for GDM in the whole sample $(3.07 \%)$ is slightly lower than the observed prevalence for screened women (3.31\%). Meanwhile, any significant classification bias is unlikely due to the fact that all the variables used are well defined in most cases, both in the birth register and in the mothers' medical records.

The aim of our study was not to take a firm position either in favour of or against selective or systematic screening for GDM, but rather to simply assess how the screening strategy used might affect the number of gravidae who would be exempt for screening, and the number of cases diagnosed. The subject of GDM screening as a public health strategy calls for a deeper and more thorough analysis than the one presented here. The choice of one technique or another does 
not only depend on the number of women screened or of cases diagnosed; the effects of the disease on the mother and the newborn, the effectiveness of the treatment, and the cost-benefit relationship of the programme should be assessed. In this sense, the clinical importance of GDM and the magnitude of its impact on mother and offspring is a controversial matter, and therefore about the overall utility of the GDM diagnosis and treatment (37-39). The room for debate appears even greater when we consider the wide definition of GDM, the different criteria used for its diagnosis and the role of other risk factors involved both in the neonatal period and the disease itself. What is needed, at this point, is conclusive prospective research to determine the actual costs of the different types of screening per se, the accuracy of the diagnoses and medical treatment of confirmed cases of GDM, beginning with the need to unify the screening and diagnostic criteria for this difficult topic.

In conclusion, GDM prevalence among low-risk gravidae may run from $0.5 \%$ to $0.6 \%$ in a general obstetric population, depending on the age cutoff used in defining risk factors (25 or 30 years respectively). Prevalence would be roughly six times higher in a high-risk obstetric population. Rigorous studies are now needed to properly assess the usefulness and cost-effectiveness of GDM screening and diagnosis. The prevalence we observed among low-risk women, however, would seem to suggest that selective screening is desirable only when fairly restrictive criteria are applied in defining the gravidae at risk and, therefore, a significant proportion of the population is exempt from screening.

\section{Acknowledgements}

This research was supported in part by the Fondo de Investigaciones Sanitarias (Fund for Health Research in Spain), grant no. 97/2096.0. We thank Jean Sanders for her help in translating and editing the manuscript.

\section{References}

1 National Diabetes Data Group, Classification and diagnosis of diabetes mellitus and other categories of glucose intolerance. Diabetes 197928 1039-1057.

2 WHO Study Group on Prevention of Diabetes Mellitus. Prevention of diabetes mellitus, Report of a WHO Study Group. Technical Report Series 844. Geneva: World Health Organisation, 1994.

3 American Diabetes Association. Report of the Expert Committee on the Diagnosis and Classification of Diabetes Mellitus. Diabetes Care 199720 1183-1197.

4 Persson B \& Hanson U. Neonatal morbidities in gestational diabetes mellitus. Diabetes Care 199821 (Suppl 2) B79-B84.

5 Mello G, Paretti E, Mecacci F, Lucchetti R, Lagazio C, Pratesi M et al. Risk factors for fetal macrosomia: the importance of a positive oral glucose challenge test. European Journal of Endocrinology $199713727-33$.
6 Dornhorst A. Implications of gestational diabetes for the health of the mother. British Journal of Obstetrics and Gynaecology 1994101 286-290.

7 Rizzo T, Metzger BE, Burns WJ \& Burns K. Correlations between antepartum maternal metabolism and intelligence of offspring. New England Journal of Medicine 1991325 911-916.

8 Pettitt DJ, Bennett P, Saad MF, Charles MA, Nelson RG \& Knowler WC. Abnormal glucose tolerance during pregnancy in Pima Indian women: long-term effects on offspring. Diabetes 199140 (Suppl 2) 126-130.

9 Beisher NA, Wein P, Sheedy MT, Werther GA \& Gold H. Maternal glucose tolerance and obstetric complication in pregnancies in which the offspring developed type I diabetes. Diabetes Care $19948832-834$.

10 Schaefer UM, Songster G, Xiang A, Berkowitz K, Buchanan TA \& Kjos SL. Congenital malformations in offspring of women with hyperglycemia first detected during pregnancy. American Journal of Obstetrics and Gynecology 1997177 1165-1171.

11 Hadden DR. Geographic, ethnic and racial variations in the incidence of gestational diabetes mellitus. Diabetes 198534 (Suppl 2) $8-12$.

12 Coustan DR. Methods of screening for and diagnosis of gestational diabetes. Clinics in Perinatology 199320 593-602.

13 Magee MS, Walden CE, Benedetti TJ \& Knopp RH. Influence of diagnostic criteria on the incidence of gestational diabetes and perinatal morbidity. Journal of the American Medical Association $1993269609-615$.

14 American College of Obstetricians and Gynecologists (ACOG). Diabetes and pregnancy. In ACOG Technical Bulletin 200, Washington DC, USA, 1994.

15 Lavin JP Jr. Screening of high-risk and general populations for gestational diabetes. Diabetes 198534 (Suppl 2) 24-27.

16 Berkowitz GS, Lapinski RH, Wein R \& Lee D. Race/ethnicity and other risk factors for gestational diabetes. American Journal of Epidemiology $1992135965-973$.

17 Dornhorst A, Paterson CM, Nicholls JS, Wadsworth J, Chiu DC, Elkeles RS et al. High prevalence of gestational diabetes in women from ethnic minority groups. Diabetic Medicine 19929 $820-825$.

18 Weijers RNM, Bekedam DJ \& Oosting H. The prevalence of type 2 diabetes and gestational diabetes mellitus in an inner city multiethnic population. European Journal of Epidemiology $1998 \mathbf{1 4}$ 693-699.

19 Diabetes care and research in Europe. The Sant Vicent Declaration. Giornale Italiano di Diabetologia 199010 (Suppl 1) 143-144.

20 Dirección General de Salud Pública, Junta de Andalucía. Manual de Atención al Embarazo, Parto y Puerperio (Guidelines for Pregnancy, Delivery and Puerperal Care). Junta de Andalucía: Consejería de Salud, 1994.

21 Boletín Oficial de la Junta de Andalucía. Orden del 24 de Octubre de 1986, por la que se Establece el Libro Registro de Partos y Recién Nacidos (Order of 24 October 1986, on the Birth Register of Deliveries and Newborns). Boletín Oficial de la Junta de Andalucía $19861073729-3732$.

22 Preventive Service Task Force. Screening of diabetes mellitus. In Guide to Clinical Preventive Services, edn 2, ch 19, pp 193-280. Baltimore: Williams \& Wilkins, 1996.

23 Danielko-Dixon DR, Van Winter JT, Nelson EL \& Ogburn PL. Universal versus selective gestational screening: application of 1997 American Diabetes Association recommendations. American Journal of Obstetrics and Gynecology 1999181 798-802.

24 Corcoy R, Cerqueira MJ, Codina M, Ordóñez J, de Leiva A \& Cabero L. Diagnóstico de la diabetes gestacional. Importancia del screening rutinario e importancia relativa de los factores de riesgo. Avances en Diabetología 19881 90-94.

25 Díaz JJ, Grande C, Pallardo LF, de la Morena ML \& Ibars MT. Detección de la diabetes gestacional con la prueba de $50 \mathrm{~g}$ de glucosa: prevalencia y relación con factores de riesgo. (Screening for gestational diabetes with the $1 \mathrm{~h} 50-\mathrm{g}$ glucose test: prevalence and relationship with risk factors). Medicina Clinica 198993 41-45. 
26 Pallardo LF \& Grande C. Diabetes gestacional. (Gestational diabetes). Endocrinología 199239 89-101.

27 Coustan DR, Nelson C, Carpenter MW, Carr SR, Rotondo L \& Widness JA. Maternal age and screening for gestational diabetes: a population based study. Obstetrics and Gynecology 198973 557-561.

28 Green JR, Pawson IG, Schumacher LB, Perry J \& Kretchmer N. Glucose tolerance in pregnancy: ethnic variation and influence of body habitus. American Journal of Obstetrics and Gynecology $199016386-92$.

29 Wen SW, Liu S, Kramer MS, Joseph KS, Levitt C, Marcoux S et al. Impact of prenatal glucose screening on the diagnosis of gestational diabetes and on pregnancy outcomes. American Journal of Epidemiology $2000 \mathbf{1 5 2} 1009-1014$.

30 Weeks JW, Major CA, De Veciana M \& Morgan M. Gestational diabetes: does the presence of risk factors influence perinatal outcome? American Journal of Obstetrics and Gyncecology 1994171 1003-1007.

31 Casey BM, Lucas MJ, McIntere DD \& Leveno KJ. Pregnancy outcomes in women with gestational diabetes compared with the general obstetric population. Obstetrics and Gynecology $1997 \mathbf{9 0}$ $869-873$.

32 McFarland KF \& Case CA. The relationship of maternal age on gestational diabetes. Diabetes Care 19858 598-600.

33 Naylor CD, Sermer M, Chen E \& Farine D. Selective screening for gestational diabetes mellitus. New England Journal of Medicine $19973371591-1596$.

34 Solomon CG, Willet WC, Carey VJ, Rich-Edwards J, Hunter DJ, Colditz GA et al. A prospective study of pregravid determinants of gestational diabetes mellitus. Journal of the American Medical Association $1997 \mathbf{2 7 8} 1078-1083$.
35 Sermer M, Naylor CD, Gare DJ, Kenshole AB, Ritchie JW, Farine D et al. Impact of time since last meal on the gestational diabetes challenge test. The Toronto Tri-Hospital Gestational Diabetes Project. American Journal of Obstetrics and Gynecology 1994 $171607-616$.

36 Buekens P. Prenatal glucose screening and gestational diabetes. American Journal of Epidemiology 2000152 1015-1016.

37 Hunter DJS \& Keirse MJNC. Gestational diabetes. In Effective Care in Pregnancy and Childbirth, ch. 25, pp 403-410. Eds I Chalmers, M Enkin \& MJNC Keirse. New York: Oxford University Press, 1991.

38 Walkinshaw SA. Diet - insulin vs diet alone for gestational diabetes. In Pregnancy and Childbirth Module of the Cochrane Database of Systematic Reviews (updated 1 September 1997). Available in The Cochrane Library (database on disk and CDROM). Eds MW Enkin, MJNC Keirse, MJ Renfrew \& C Crowther. Oxford: The Cochrane Collaboration; issue 2. Updated software; 1995. Updated quarterly.

39 Walkinshaw SA. Dietary regulation for gestational diabetes. In Pregnancy and Childbirth Module of the Cochrane Database of Systematic Reviews (updated 1 September 1997). Available in The Cochrane Library (database on disk and CDROM). Eds JP Neilson, ED Hodnett \& ED Hofmeyr. Oxford: The Cochrane Collaboration; issue 4. Updated software; 1997. Updated quarterly.

Received 16 May 2001

Accepted 20 February 2002 